\title{
Investigation of Low Power Operation in a Loop Heat Pipe
}

\author{
Jentung $\mathrm{Ku}$, Laura Ottenstein \\ NASA Goddard Space Flight Center \\ Code 545 \\ Greenbelt, MD 20771 \\ (301)286-3130 \\ jentung.ku@gsfc.nasa.gov \\ Paul Rogers \\ Army TEC \\ Warren, MI \\ Kwok Cheung \\ Naval Research Laboratory \\ Washington, D.C.
}

\begin{abstract}
This paper presents test results of an experimental study of low power operation in a loop heat pipe. The main objective was to demonstrate how changes in the vapor void fraction inside the evaporator core would affect the loop behavior. The fluid inventory and the relative tilt between the evaporator and the compensation chamber were varied so as to create different vapor void fractions in the evaporator core. The effect on the loop start-up, operating temperature, and capillary limit was investigated. Test results indicate that the vapor void fraction inside the evaporator core is the single most important factor in determining the loop operation at low powers.
\end{abstract}

\section{Introduction}

Loop heat pipes are versatile two-phase heat transfer devices which can transport large amounts of heat loads over long distances with small temperature differences. As shown in Figure 1, a major feature of the LHP design is the physical proximity of the compensation chamber to the evaporator with a secondary wick connecting both elements. Such a construction gives the LHP many advantages, including self-start without pre-conditioning, and robust operation even in the presence of vapor bubbles. Unfortunately, this design also leads to some peculiar behaviors of LHPs at low powers.

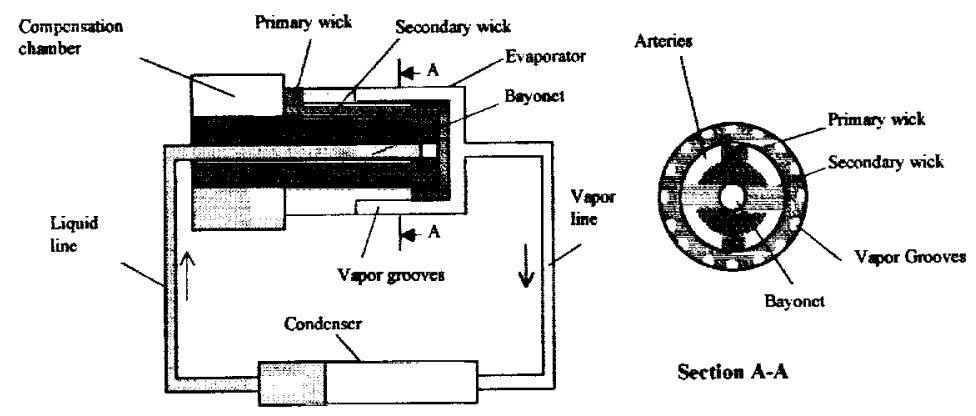

Figure 1. Schematic of a Loop Heat Pipe

Because the compensation chamber forms an integral part of the evaporator, some heat leak from the evaporator to the compensation chamber is inevitable. The heat leak follows two paths. One is by conduction along the axial direction through the hermetic case. The other is by conduction in the radial direction through the primary wick into the fluid inside the evaporator core. When the evaporator core is completely filled with liquid, the axial heat conduction through the hermetic case dominates, and is usually 
small. When the evaporator core contains vapor, the evaporator core becomes part of the compensation chamber, and the heat leak through the primary wick becomes the dominating factor and can be very large. Furthermore, the higher the vapor void fraction inside the evaporator core, the larger the heat leak.

An experimental study was conducted to illustrate how the heat leak might vary with the vapor fraction in the evaporator core and affect the LHP operation. Test variables included the fluid inventory, tilt between the evaporator and the compensation chamber, evaporator heat load, and condenser sink temperature. Their effects on the LHP operation such as start-up, power cycle, capillary limit, and sensitivity to the external pressure drop were investigated. Descriptions of the test article, test setup, tests performed, and test results are presented in the following sections.

\section{Test Article and Test Set-up}

The test article is a modification of the NRL LHP [1], and is shown schematically in Figure 2. The evaporator and compensation chamber are both made of stainless steel with an outer diameter of $25.4 \mathrm{~mm}$ and have lengths of $30.5 \mathrm{~mm}$ and is $12.7 \mathrm{~mm}$, respectively. The primary wick is made of sintered powder nickel with a pore size of 2 microns and a permeability of $1.4 \times 10^{-14} \mathrm{~m}^{2}$. The vapor line has an inside diameter of $3.34 \mathrm{~mm}$ and a length of $1.94 \mathrm{~m}$ while the liquid line has an inside diameter of $1.75 \mathrm{~mm}$ and a length of $2.1 \mathrm{~m}$. The condenser line has an inside diameter of $3.86 \mathrm{~mm}$ and is serpentined into three passes to yield a total length of $1.99 \mathrm{~m}$. Anhydrous ammonia is used as the working fluid.

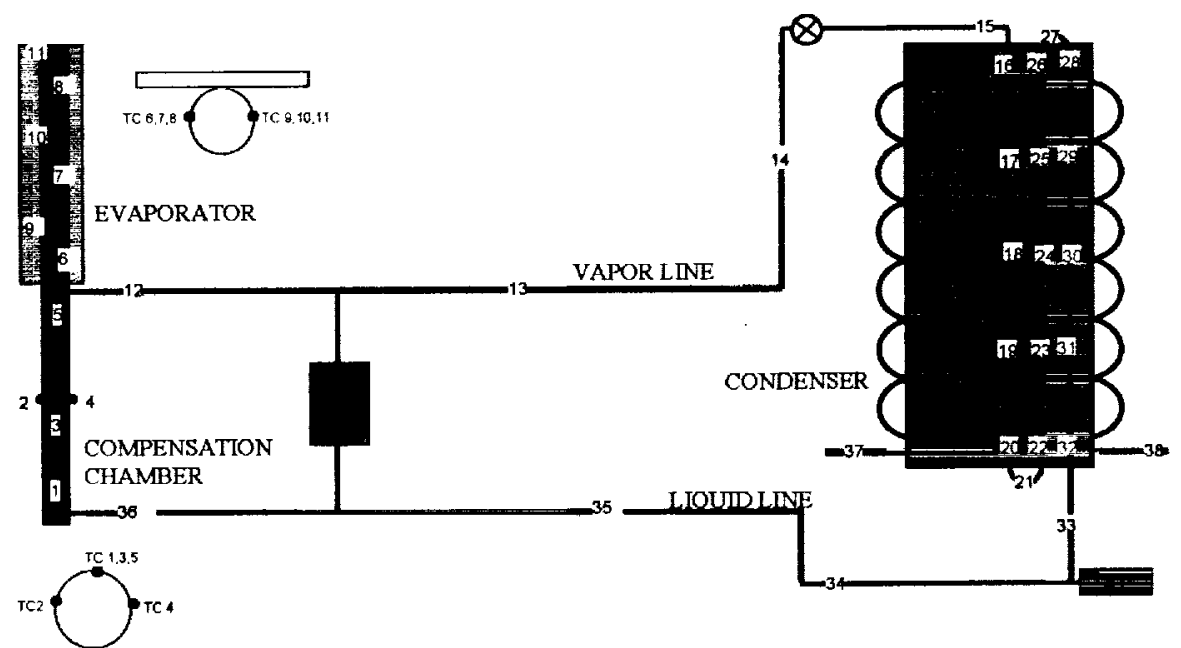

Figure 2. Schematic of the Modified NRL LHP with Thermocouple Locations

An aluminum block with two cartridge heaters is attached to the evaporator to provide variable power up to $1200 \mathrm{~W}$. A MTNCO heater is attached to the compensation chamber for temperature control, when needed. The condenser is mounted on an aluminum cold plate with imbedded coolant channels and is cooled by a refrigerator. A total of 39 thermocouples are installed to monitor loop temperatures. A differential pressure transducer is used to measure the external pressure drop across the evaporator between the vapor outlet and the liquid inlet. An absolute pressure transducer is used to monitor the loop saturation pressure. A metering valve is installed on the vapor line. By closing the valve to different positions, additional pressure drops can be added to the total pressure drop.

A data acquisition system consisting of two dataloggers, two personal computers, two CRT monitors, and the Labview software program is used to monitor and store data. One monitor and computer display and store the temperature and power data every second. The other monitor and computer display and store the pressure drop data every hundredth of a second. The simultaneous collection and display of temperature and differential pressure data proves to be crucial in the understanding of interactions between various elements in LHP operation. 


\section{Test Performed and Results}

It is postulated that the heat leak is strongly dependent upon the vapor void fraction inside the evaporator core. It is further postulated that the higher the vapor void fraction, the higher the heat leak. Based on these postulates, it was demonstrated over and over again throughout the test program that the heat leak from the evaporator to the compensation chamber is the single most important factor in determining the LHP behavior in all aspects of its low power operation. For a given LHP, the vapor void fraction inside the evaporator core is affected by the amount of fluid inventory, the relative tilt between the evaporator and the compensation chamber, and temperatures in various components of the LHP. In all tests described below, three different amounts of ammonia are used in this test program: 83 grams, 100 grams, and 113 grams. These volumes represent vapor void fractions of $83 \%, 50 \%$ and $30 \%$ in the compensation chamber/ evaporator core, respectively, assuming that the vapor line, condenser and liquid line are all completely filled with liquid at $273 \mathrm{~K}$. For each fluid inventory, there are three tilts: evaporator higher than the compensation chamber by $6.35 \mathrm{~mm}$ (negative tilt or adverse tilt), flat, and compensation chamber higher than the evaporator by $6.35 \mathrm{~mm}$ (positive tilt or favorable tilt), all measured from the compensation end to the evaporator end. The combination of the fluid inventory and the tilt will affect the vapor void fraction in the evaporator core even though no direct measurements could be made.

Because several variables are involved in each test, for ease of description the test conditions will be presented in the following manner: (fluid inventory/ tilt/ heat load/ sink temperature). For example, $(83 \mathrm{~g} /$ $+6.35 \mathrm{~mm} / 100 \mathrm{~W} / 273 \mathrm{~K}$ ) means the test was conducted with 83 grams of fluid in the loop, a tilt of $+6.35 \mathrm{~mm}, 100 \mathrm{~W}$ heat load to the evaporator, and $273 \mathrm{~K}$ sink temperature. The test program lasted for more than five months, collecting over 800 hours of data. This paper only gives a summary of the results. Details of various tests will be presented in separate papers in the future.

\section{$\underline{\text { Start-up }}$}

There are four possible scenarios for LHP start-up [2,3], depending on the two-phase compositions in the evaporator core (inside the primary wick) and evaporator grooves (outside the primary wick). All four scenarios were observed in this test program. In addition, a fifth start-up phenomenon, a long-term sustaining reverse flow, was also observed and will be described later.

LHPs can start rather quickly and reliably as long as a large heat load is applied. This can be attributed to the quick rise of the evaporator temperature above the compensation chamber temperature, and the circulation of a large flow of the working fluid. Under such a condition, there is ample liquid subcooling to balance the heat leak from the evaporator to the compensation chamber regardless which start-up scenario prevails. When the heat load is small, however, the heat leak becomes large compared to the total heat load. Two kinds of start-up difficulties can occur. First, the evaporator may never be able to build the necessary superheat for nucleate boiling if the vapor grooves are completely flooded with liquid and the evaporator core contains vapor. Second, even if vapor is generated and a flow circulation is established, the flow rate is so small that not enough subcooling can be provided to the compensation chamber to overcome the heat leak. Consequently, both the evaporator and the compensation chamber temperatures will rise together, far exceeding the maximum allowable temperature.

In this test program, for each combination of the fluid inventory and tilt, the start-up test was conducted with the following heat loads: $5 \mathrm{~W}, 25 \mathrm{~W}, 50 \mathrm{~W}, 100 \mathrm{~W}$, and $200 \mathrm{~W}$, and the following condenser sink temperatures: $230 \mathrm{~K}, 250 \mathrm{~K}, 260 \mathrm{~K}, 270 \mathrm{~K}, 280 \mathrm{Kand} 293 \mathrm{~K}$. Each morning, the loop was set to the desired tilt, and the chiller was set to the desired set point temperature. After the condenser had reached a steady state, a heat load was applied to the evaporator. No pre-conditioning of the evaporator or compensation chamber was implemented in most tests although a few tests were conducted by first raising the compensation chamber temperature to a desired set point.

Test results show that the loop could start with $100 \mathrm{~W}$ or $200 \mathrm{~W}$ regardless of the fluid inventory, tilt, or condenser sink temperature. For heat loads less than $100 \mathrm{~W}$, start-up was highly dependent upon the fluid inventory and the tilt. With a fluid inventory of 83 grams, the loop could not start successfully below $100 \mathrm{~W}$ with all three tilts. Figure 3 shows the loop temperature in the $(83 \mathrm{~g} /+6.35 \mathrm{~mm} / 25 \mathrm{~W} / 270 \mathrm{~K})$ start-up 
test. The flow circulation started as soon as the heat load was applied to the evaporator as evidenced by an increase of the vapor line temperature TC15 and a decrease of the liquid line temperature TC33. However, at such a low fluid inventory, the vapor void fraction in the evaporator core was high, resulting in a high heat leak. Because the small mass flow rate at $25 \mathrm{~W}$, there was not enough subcooling to compensate for the heat leak. Thus, the evaporator and compensation chamber temperature continued to rise. After the saturation temperature rose above $323 \mathrm{~K}$, the heat load was increased to $100 \mathrm{~W}$. The saturation temperature dropped immediately and eventually reached a steady temperature at $294 \mathrm{~K}$. The higher mass flow rate at $100 \mathrm{~W}$ brought larger subcooling to the compensation chamber. It could also help collapse vapor bubbles inside the evaporator core. The heat load was then reduced to $25 \mathrm{~W}$. The saturation temperature increased and reached a new steady value of $309 \mathrm{~K}$, much lower than when the loop was first started at $25 \mathrm{~W}$. The reason for this is that the evaporator core had been filled with liquid at $100 \mathrm{~W}$ and changed little even after the heat load was reduced to $25 \mathrm{~W}$. Furthermore, as the heat load increased to $100 \mathrm{~W}$ again, the loop saturation temperature was $289 \mathrm{~K}$, which was 5 degrees lower than previous value at the same heat load. Such a temperature hysteresis was observed in many LHPs [1,3-6]. It appeared that the vapor void fraction continued to decrease in this test. For comparison, when the same test was conducted with 100 grams or 113 grams of fluid inventory, the temperature hysteresis occurred only at $25 \mathrm{~W}$ after the start-up and the subsequent power cycle of $25 \mathrm{~W} / 100 \mathrm{~W} / 25 \mathrm{~W}$. As the power cycle continued, the temperatures were repeatable at $25 \mathrm{~W}$ and $100 \mathrm{~W}$, respectively. For start-up with a heat load of $50 \mathrm{~W}$, the flow circulation started immediately, but the loop temperature reached a steady temperature only during some of the tests. After a power cycle of $50 \mathrm{~W} / 200 \mathrm{~W} / 50 \mathrm{~W}$, the loop reached a steady temperature that was lower than when the loop started. The phenomenon was similar to the $25 \mathrm{~W}$ start-up and subsequent power cycle. For startups with $100 \mathrm{~W}$ or $200 \mathrm{~W}$, the loop always started immediately and eventually reached a steady state.

Figure 3. See plots at the end of the text.

At 83 grams, a reverse flow was also observed during start-up. A reverse flow will occur when the vapor grooves are filled with liquid and the evaporator core contains vapor. As the heat load is applied to the evaporator, part of the heat goes into heating up the liquid in the vapor groove and part of the heat is conducted through the primary wick to vaporize the liquid in the evaporator core. The reverse flow will continue until vapor is generated in the vapor grooves to initiate a forward flow. Once the forward flow is established, it is easier for the vapor to be generated on the outer surface than the inner surface of the primary wick. Thus, the forward flow will prevail. The reverse flow can happen at any heat load. With high heat loads, the forward flow is established so quickly that the reverse flow only lasts for seconds. At low heat loads, however, the reverse flow may last for a long time. Figure 4 shows the $(83 \mathrm{~g} /-6.35 \mathrm{~mm} /$ $25 \mathrm{~W} / 290 \mathrm{~K}$ ) start-up where the reverse flow lasted for many hours, and could presumably continue forever. The forward flow was established only after a heat load of $100 \mathrm{~W}$ was applied to the evaporator. After a steady temperature of $299 \mathrm{~K}$ was reached at $100 \mathrm{~W}$, the heat load was reduced to $25 \mathrm{~W}$. The forward flow continued and the loop reached a new steady temperature of $296 \mathrm{~K}$. Note that the loop operating temperature was lower at $25 \mathrm{~W}$ than at $100 \mathrm{~W}$ because the sink temperature was near the ambient temperature and the condenser was fully utilized under both heat loads.

Figure 4. See plots at the end of the text. 1/8/01.

When the loop was charged with 100 grams or 113 grams, the loop always started successfully with a heat load of $25 \mathrm{~W}$ or higher, and reached a steady temperature below $310 \mathrm{~K}$ regardless of the tilt and the sink temperature. The loop even started with $5 \mathrm{~W}$ in most case with a steady temperature below $310 \mathrm{~K}$. Nevertheless, for heat loads less than $100 \mathrm{~W}$, the loop often reached a lower steady temperature after a power cycle such as $25 \mathrm{~W} / 100 \mathrm{~W} / 25 \mathrm{~W}$ than when the loop first started. Figure 5 shows the loop temperatures in the $(100 \mathrm{~g} /+6.35 \mathrm{~mm} / 5 \mathrm{~W} 270 \mathrm{~K})$ start-up and the subsequent power cycle of $5 \mathrm{~W} / 100 \mathrm{~W} /$ $800 \mathrm{~W} / 100 \mathrm{~W} / 5 \mathrm{~W}$. With a favorable tilt and a relatively large fluid inventory, the loop did not show any hysteresis at $100 \mathrm{~W}$ or $5 \mathrm{~W}$.

Figure 5. See plots at the end of the text.

In all successful start-ups that led to a steady saturation temperature, the saturation temperature was always lower with a higher fluid inventor and/or a favorable tilt. Because a higher fluid inventory and/or a 
favorable tilt means the evaporator core would have a higher probability of being filled with more liquid, the heat leak would be reduced. The effect of the vapor void fraction on the heat leak and the loop start-up was obvious. The start-up with low heat loads was investigated very extensively in this study and details will be presented in a separate paper in the future.

\section{Power Cycle}

Each start-up test was always followed by a power cycle test. Typical power cycles include $5 \mathrm{~W} / 100 \mathrm{~W} / 5 \mathrm{~W}$, $25 \mathrm{~W} / 100 \mathrm{~W} / 25 \mathrm{~W}, 50 \mathrm{~W} / 200 \mathrm{~W} / 50 \mathrm{~W}$, and $100 \mathrm{~W} / 800 \mathrm{~W} / 100 \mathrm{~W}$. For start-ups with heat loads less than $100 \mathrm{~W}$, the phenomena of temperature hystereses have been described above. For $100 \mathrm{~W}$ start-ups, the temperature hysteresis was much less noticeable and occurred only at 83 grams fluid inventory. The results were consistent with the postulate regarding the vapor void fraction and the heat leak.

\section{$\underline{\text { Sink Temperature Cycle }}$}

The sink temperature cycle test was conducted by cycling the sink temperature between $230 \mathrm{~K}$ and $290 \mathrm{~K}$ while keeping the evaporator heat load constant at $5 \mathrm{~W}, 25 \mathrm{~W}, 50 \mathrm{~W}, 100 \mathrm{~W}$ or $200 \mathrm{~W}$. As the sink temperature changes, the liquid returning to the compensation chamber also changes. Consequently, the compensation chamber temperature will change in order to maintain the energy balance. In this test, the compensation chamber temperature did change appreciably with the sink temperature for heat loads of $50 \mathrm{~W}$ or higher. For heat loads of $25 \mathrm{~W}$ or $5 \mathrm{~W}$, the compensation chamber temperature changed little with the sink temperature. This can be explained as follows. At a low heat load, the mass flow was small. As the liquid exited the condenser and flowed along the liquid line, its temperature rose to near the ambient temperature due to parasitic heat gains regardless of the sink temperature. It is as if the condenser were isolated from the compensation chamber. In other words, the sink temperature would affect the compensation chamber temperature only to the extent that it could affect the temperature of the liquid returning to the compensation chamber. Figure 6 illustrates that the compensation chamber temperature changed less than 5 degrees as the sink temperature cycled between $230 \mathrm{~K}$ and $290 \mathrm{~K}$ in the $(100 \mathrm{~g} / 0 \mathrm{~mm} /$ $25 W)$ test. The effect of the sink temperature diminished as the heat load decreased. In fact, the compensation chamber temperature was dependent more on the ambient temperature than the sink temperature at $5 \mathrm{~W}$.

Figure 6. See plots at the end of the text. Sink temperature cycle test.

\section{$\underline{\text { Saturation Temperature versus Pressure Drop }}$}

In two-phase systems, the saturation temperature is directly related to the saturation pressure. Because both the compensation chamber and the evaporator outer grooves contain two-phase fluid, a relationship exists between the temperature difference and the pressure difference, as can be expressed by the ClausiusClapeyron equation:

$$
\Delta \mathrm{P}=\lambda\left(\mathrm{T}_{\mathrm{e}}-\mathrm{T}_{\mathrm{cc}}\right) /\left(\mathrm{T}_{\mathrm{cc}} \Delta \mathrm{v}\right)
$$

where $\lambda$ and $\Delta v$ are the latent heat of vaporization and difference in the vapor and liquid specific volumes, respectively, $T_{e}$ and $T_{c c}$ are the saturation temperatures of two-phase fluid in the vapor grooves and compensation chamber, respectively, and $\Delta \mathrm{P}$ is equal to the total system pressure drop minus the pressure drop through the primary wick.

When an external pressure drop is imposed upon the LHP, such as the static pressure head due to an adverse elevation, the evaporator temperature must increase in order to satisfy the thermodynamic conditions between the evaporator and the compensation chamber. This will result in a higher heat leak to the compensation chamber. When the evaporator heat load is large, the high mass flow rate can easily compensate for the additional heat leak, and there is little effect on the operating temperature. When the evaporator heat load is small, however, the increased heat leak can only be overcome by an increase of the liquid subcooling. For a fixed heat load; the liquid subcooling can be increased only by raising the 
compensation chamber temperature. Thus, a moderate adverse elevation can significantly raise the loop operating temperature.

In this study, an external pressure was imposed upon the loop by closing the metering valve on the vapor line to different positions. Tests were performed by applying a constant power of $100 \mathrm{~W}$ or $200 \mathrm{~W}$ to the evaporator at a constant sink temperature of $280 \mathrm{~K}$. The metering valve was first fully open, then was closed to yield an external pressure drop of $3400 \mathrm{~Pa}, 7000 \mathrm{~Pa}$, and $20000 \mathrm{~Pa}$. Figure 7 shows the operating temperature as a function of the externally imposed pressure drop in the $(83 \mathrm{~g} /-6.35 \mathrm{~mm} / 100 \mathrm{~W} / 280 \mathrm{~K})$ test. It is clearly seen that the loop saturation temperature increased as the external pressure drop increased to $3400 \mathrm{pa}$ and $7000 \mathrm{~Pa}$. When the fluid inventory increased to $100 \mathrm{grams}$ and $113 \mathrm{grams}$, the temperature changed very little at a pressure drop of $3400 \mathrm{~Pa}$. Thus tests were conducted with pressure drops of $7000 \mathrm{~Pa}$ and $20000 \mathrm{~Pa}$. Figure 8 show the temperature versus pressure drop in the $(113 \mathrm{~g} /+6.35 \mathrm{~mm} / 100 \mathrm{~W} / 280 \mathrm{~K})$ test. In this case, it appeared that the evaporator core was nearly flooded with liquid. Thus raising the external pressure drop from $300 \mathrm{~Pa}$ to $7000 \mathrm{~Pa}$ only raised the loop saturation temperature slightly because the heat leak was low under either condition. In fact, changing the external pressures from $300 \mathrm{~Pa}$ to $20000 \mathrm{~Pa}$ only raised the loop saturation temperature from $291 \mathrm{~K}$ to $293 \mathrm{~K}$.

Figure 7. See plots at the end of the text. Temperature vs Pressure Drop.

Figure 8. Temperature vs Pressure Drop.

Figures 7 and 8 illustrate the effect of the vapor void fraction in the evaporator on the heat leak under the same test conditions. When the loop was charged with less fluid, the vapor void fraction in the evaporator was higher, leading to a higher heat leak and a higher saturation temperature when the same pressure drop was imposed. Test results also verified the effect of the tilt. The temperature rise due to an increasing pressure drop was more pronounced as tilt changed from a favorable $+6.35 \mathrm{~mm}$ tilt, to a flat configuration, and then to an adverse $-6.35 \mathrm{~mm}$ tilt. In addition, test result show that the increase in the saturation temperature due to an increasing pressure drop was less at $200 \mathrm{~W}$ than at $100 \mathrm{~W}$ because the higher mass flow rate could better compensate for the heat leak.

\section{Capillary Limit}

The maximum capillary pressure that the primary wick is able to sustain can be expressed as

$$
\Delta \mathrm{P}_{\text {cap, } \max }=2 \sigma / \mathrm{r}_{\mathrm{p}}
$$

where $\sigma$ is the surface tension of the working fluid and $r_{p}$ is the radius of the wick pores. When the total pressure drop across the primary wick exceeds its capillary limit, vapor will penetrate through the wick and reach the evaporator core and the compensation chamber. In a capillary pumped loop (CPL), the deprime of the wick will lead to a temperature excursion and catastrophic failure if the heat load is not removed or reduced. In an LHP, the vapor penetration will lead to a rapid increase of the compensation chamber and evaporator temperatures during the transient. However, the loop will continue to operate because the evaporator core can tolerate vapor presence and its temperature is always equal to the saturation temperature. The loop can even reach a new steady state if the total pressure drop does not exceed the capillary pressure by too much at the moment of vapor penetration.

The pore size of the primary wick is about $1.2 \mu \mathrm{m}$ and can sustain a pressure drop up to $32000 \mathrm{~Pa}$ at $300 \mathrm{~K}$. A high power test was conducted with $1200 \mathrm{~W}$ to the evaporator, and the loop continued to operate without any problems. No higher heat loads were applied because $1200 \mathrm{~W}$ was the maximum power that the heater could deliver. In order to investigate the capillary limit, an external pressure drop was added to the loop by closing the metering valve. Several different kinds of capillary limit tests were conducted. One method was to close the metering valve to yield an external pressure drop of $17000 \mathrm{~Pa}$ at a heat load of $200 \mathrm{~W}$ and a sink temperature of $260 \mathrm{~K}$. The heat load was then increased with $50 \mathrm{~W}$ increments until vapor penetration occurred. 
Figure 9 shows the loop temperatures as a function of the heat load. Note that as the heat load increased to $350 \mathrm{~W}$, the external pressure drop reached a maximum of $32000 \mathrm{~Pa}$, and suddenly decreased. At the same time, the saturation temperature TC3 increased sharply from $298 \mathrm{~K}$ to $309 \mathrm{~K}$. This is an indication that the capillary limit was exceeded and vapor penetration had occurred. The loop eventually reached a new steady state with an external pressure drop of $28000 \mathrm{~Pa}$. The external pressure drop (and hence the total pressure drop in the loop) decreased because the vapor front inside the condenser receded and the vapor pressure drops in the evaporator grooves and the vapor line decreased due to a decreasing vapor viscosity at the higher temperature. As the heat load increased to $400 \mathrm{~W}$, the loop was approaching a new steady temperature of $325 \mathrm{~K}$ with an external pressure drop of $21500 \mathrm{~Pa}$. When the heat load was reduced to $200 \mathrm{~W}$, the saturation temperature and the external pressure drop returned to approximately the same values seen in earlier part of the test, indicating the primary wick was nearly recovered. The heat load was then increased from $200 \mathrm{~W}$ directly to $400 \mathrm{~W}$, and the external pressure rose to $33000 \mathrm{~Pa}$ before vapor penetration occurred. The loop eventually reached a saturation temperature of $319 \mathrm{~K}$ and an external pressure of $21500 \mathrm{~Pa}$. Note that the loop saturation temperature was $294 \mathrm{~K}$ at $200 \mathrm{~W}$. Thus, it could sustain an external pressure drop of more than $33000 \mathrm{~Pa}$ before vapor penetrated the wick. By comparison, the loop saturation was $309 \mathrm{~K}$ and could only sustain less than $32000 \mathrm{~Pa}$ of external pressure drop prior to vapor penetration.

Figure 9. Capillary Limit

Because the surface tension is a function of the saturation temperature, the capillary limit also depends on the saturation temperature. Furthermore, the power level at which the capillary limit was exceeded was a function of the fluid inventory and the tilt because both the fluid inventory and tilt affected the heat leak and the saturation temperature under otherwise the same test conditions. The capillary limit was reached at lower heat loads when the fluid inventory was lower and/or when the evaporator was tilted above the compensation chamber. Other issues regarding the capillary limit will be discussed in detail in a separate paper.

\section{Temperature Oscillations}

Details of temperature oscillations in an LHP were given in Reference 6. One sufficient condition to cause the temperature oscillation is for the vapor front to move back and forth near the exit of the condenser. Factors that can change the vapor front position include the heat load, condenser sink temperature, and body force.

Although not a main objective of this test program, temperature oscillations were observed whenever the combination of the heat load and the sink temperature resulted in the vapor front moving back and forth at the condenser exit. For example, temperature oscillations were seen in Figure 4 at $100 \mathrm{~W}$ and in Figure 5 at $800 \mathrm{~W}$. In this test loop, temperature oscillations were also seen whenever the vapor front was at TC21 or TC27 where the condenser tube was not in direct contact with the condenser plate. Moreover, as shown in Figure 10, temperature oscillations could occur when the vapor front moved back and forth near the condenser inlet. In this case, the heat load was $5 \mathrm{~W}$ and the condenser sink was set at $250 \mathrm{~K}$. The detailed mechanism that caused the temperature oscillation was presented in Reference 3, and the same explanation can be applied to the present study.

Figure 10. Temperature oscillation with vapor front at the condenser inlet.

\section{Sudden Change of Loop Operating Temperature}

In previous tests with other LHPs, the loop could operate under steady state for one or two hours, then the saturation temperature suddenly increased or decreased by a few degrees. This phenomenon was difficult to explain or verify by examining loop temperatures alone. Sudden change of the loop operating temperature under seemingly steady conditions was also observed frequently in this study. Figure 3 shows a sudden temperature drop at 10:15, and a sudden temperature rise at 15:00. Because the pressure drop data is now available, a convincing argument can be made regarding the cause of this phenomenon. 
Figure 11 shows the loop temperature in the $(83 \mathrm{~g} /+6.35 \mathrm{~mm} / 100 \mathrm{~W} / 270 \mathrm{~K})$ test. The loop was approaching a steady state, then the saturation temperature TC3 suddenly decreased at 10:23. At the same time, the liquid line temperatures TC33 to TC 36 all decreased and the pressure drop increased to $33000 \mathrm{~Pa}$. This is an indication that vapor bubbles inside the evaporator core were collapsing or shrinking. To fill the voids, liquid was rushing into the evaporator core from the condenser, creating a large mass flow rate and a huge pressure drop. The saturation temperature TC 3 was below the ambient temperature and the vapor line temperature had been higher than TC3 because of parasitic gains due to a poor insulation. The vapor line temperature dropped to the saturation temperature when the fluid rushed into the evaporator core because there was not enough time for the vapor to gain heat from ambient. About 20 minutes later, TC3 suddenly increased by 8 degrees and the differential pressure showed a sudden dip to $-41000 \mathrm{~Pa}$. This indicated that vapor bubbles were generated inside the evaporator core. As vapor bubbles were generated, two-phase fluid or warm liquid was expelled into the condenser via the liquid return line as evidenced by a sudden increase of the liquid line temperatures. During the fast transient, cold liquid also back flowed from the condenser to the vapor line and the vapor line temperature TC15 dropped below TC3. Such a vapor generation or collapsing phenomenon was observed frequently during the course of the test program. Whenever differential pressure had a huge spike (bubble collapsing), the liquid line temperature decreased and the vapor line temperature dropped to the saturation temperature, but was never lower. Whenever the differential pressure had a huge dip (bubble generation), the liquid line temperature increased, and the vapor line temperature dropped below the saturation temperature due to a back flow of the cold liquid from the condenser.

Figure 11 shows the loop temperatures in a $(83 \mathrm{~g} /$

After the sudden increase in the saturation temperature shown in Figure 11, the loop temperature eventually came back to the same temperature as before the change. When the heat load is small, the loop temperature may never come back. Figure 12 shows loop temperatures in the $(113 \mathrm{~g} / 0 \mathrm{~mm} / 5 \mathrm{~W} / 290 \mathrm{~K})$ test. The loop was running steadily at $298 \mathrm{~K}$ during the night for more than 6 hours. Then the saturation temperature TC3 began to rise shortly after midnight. Again, the liquid line temperature suddenly increased and the vapor line temperature dropped below the saturation temperature, indicating that vapor bubbles were generated. Once vapor was generated inside the evaporator core, the heat leak increased. At such a low heat load, the vapor bubbles had no chance to collapse, and the loop saturation temperature gradually increased above $310 \mathrm{~K}$ in the next 8 hours.

Figure 12. 3/1/01 overnight and 3/2/01 test

\section{Summary and Concluding Remarks}

A comprehensive test program was conducted to investigate the low power operation of an LHP. The heat leak from the evaporator to the compensation chamber plays an important role in LHP operation with low powers. It is postulated that the heat leak is highly dependent upon the vapor fraction inside the evaporator core. Three different fluid inventories and three different tilts were incorporated into the test program so as to effect a change of the vapor fraction. Tests performed include start-up, power cycle, sink temperature cycle, capillary limit, and change of operating temperature when subjected to different pressure drops. Even though the exact void fraction could not be determined, changes in the loop operation due to change in the void fraction resulting from inventory change and tilt change were clearly demonstrated. Sudden changes in the loop saturation temperature can also be inferred as a result of vapor bubble generation or collapsing by examining changes in the differential pressure and other temperatures in the loop. It can be concluded that the void fraction inside the evaporator core is the single most important factor in determining the loop operating temperature at low heat loads. Any factors that change the void fraction will affect the loop operation in terms of the start-up, operating temperature, and capillary limit.

\section{References}

I. Cheung, M., Hoang, T., Ku, J., and Kaya, T, "Thermal Performance and Operational Characteristics of Loop Heat Pipe (NRL LHP)," SAE Paper No. 981813, $28^{\text {th }}$ International Conference on Environmental Systems, July13-16, Danvers, Massachusetts. 
2. Maidanik, Y. F., Solodovnik, N. N., and Y. G. Fershtater, "Investigation of Dynamic and Stationary Characteristics of a Loop Heat Pipe," IX International Heat Pipe Conference, May 1-5, 1995, Albuquerque, New Mexico.

3. Ku, J, "Operating Characteristics of Loop Heat Pipes," SAE Paper No. 1999-01-2007, $29^{\text {th }}$ International Conference on Environmental Systems, July 12-15, 1999, Denver Colorado.

4. Wolf, D., and Bienert, W, "Investigation of Temperature Control Characteristics of Loop Heat Pipe," SAE Paper No. 941576, $24^{\text {th }}$ International Conference on Environmental Systems, July 20-23, 1994, Friedrichshafen, Germany.

5. Kaya, T. and Ku, J., "Investigation of the Temperature Hysteresis Phenomenon of a Loop Heat Pipe," 1999 National Heat Transfer Conference, August 15-17, Albuquerque, New Mexico.

6. Ku, J., Ottenstein, L., Kaya, T., Kobel, M., Rogers, P and T. Kaya, "Temperature Oscillations in Loop Heat Pipe Operation," STAIF 2001, American Institute of Physics, Albuquerque, New Mexico, February $11-14,2001$.

\section{Acknowledgements}

The authors would like to give their sincere thanks to the following colleagues in the Thermal Engineering Laboratory at NASA Goddard Space Flight Center: Messrs. J. Dye and Mr. P. Gonzales for setting up the test loop, Messrs. R. Rector and M. Martins for helping conduct some of the tests, and Ms. A. Rector for writing the data acquisition software and making data plots. 
NRL LHP 10-17-2000

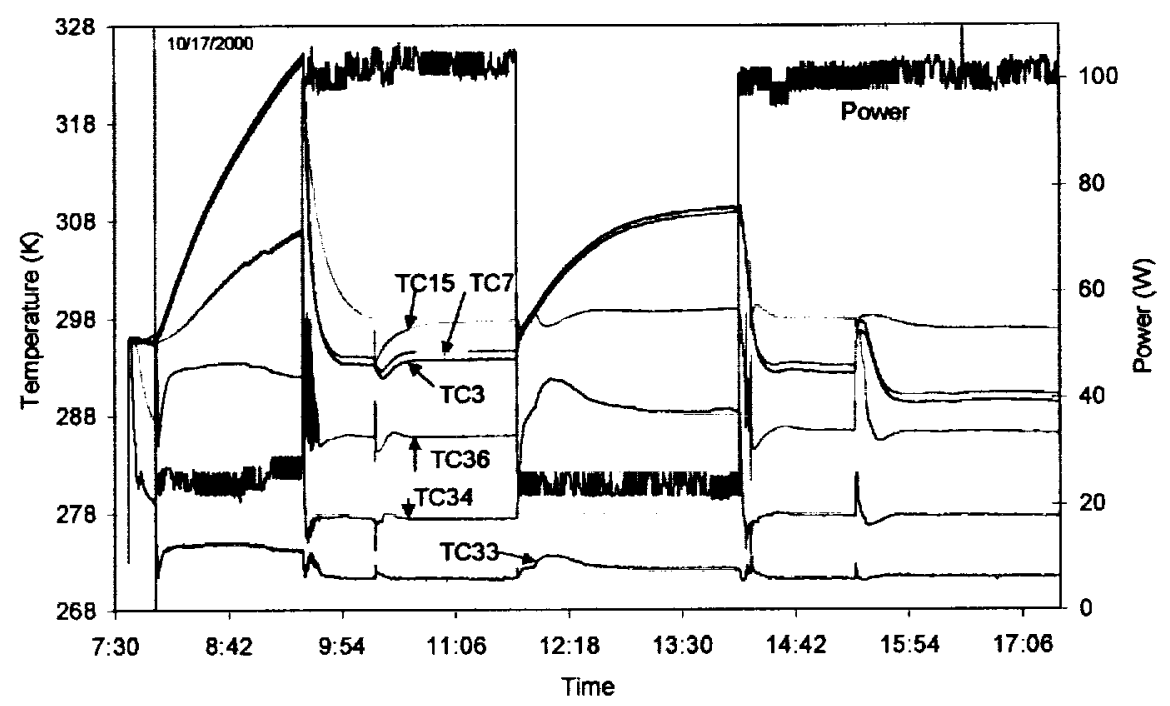

Figure 3. (10/17/00 7:30 to 17:30 with start-up and sudden temperature change at $100 \mathrm{~W}$ (TC3=CC, TC7=Evaporator, TC15=vapor line, TC34/ TC36=Liquid Line)

NRL LHP 01/08/2001

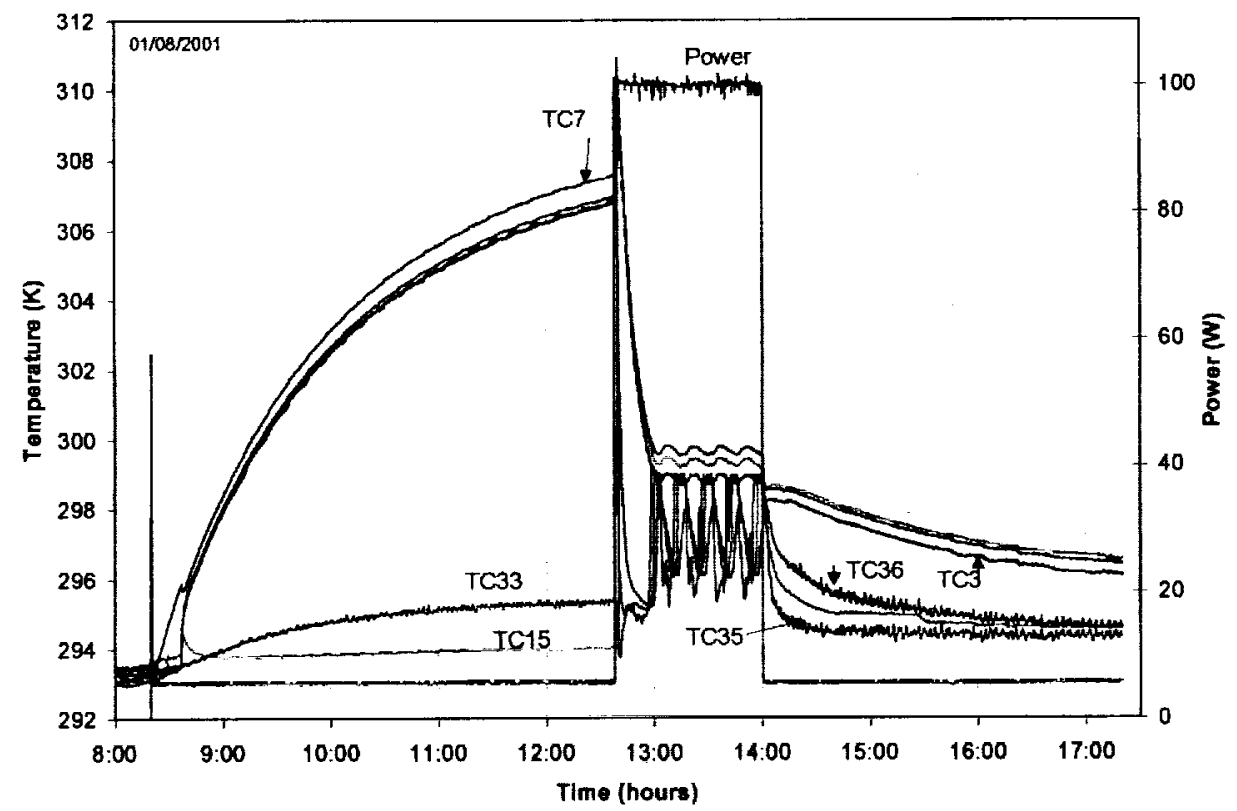

Figure 4. (1/8/01) Start-up with $100 \mathrm{~g} / 6.35 \mathrm{~mm} / 5 \mathrm{~W} / 290 \mathrm{~K}$

(TC3=CC, TC7=Evaporator, TC15=Vapor line, TC33/ TC35/ TC36=Liquid Line) 


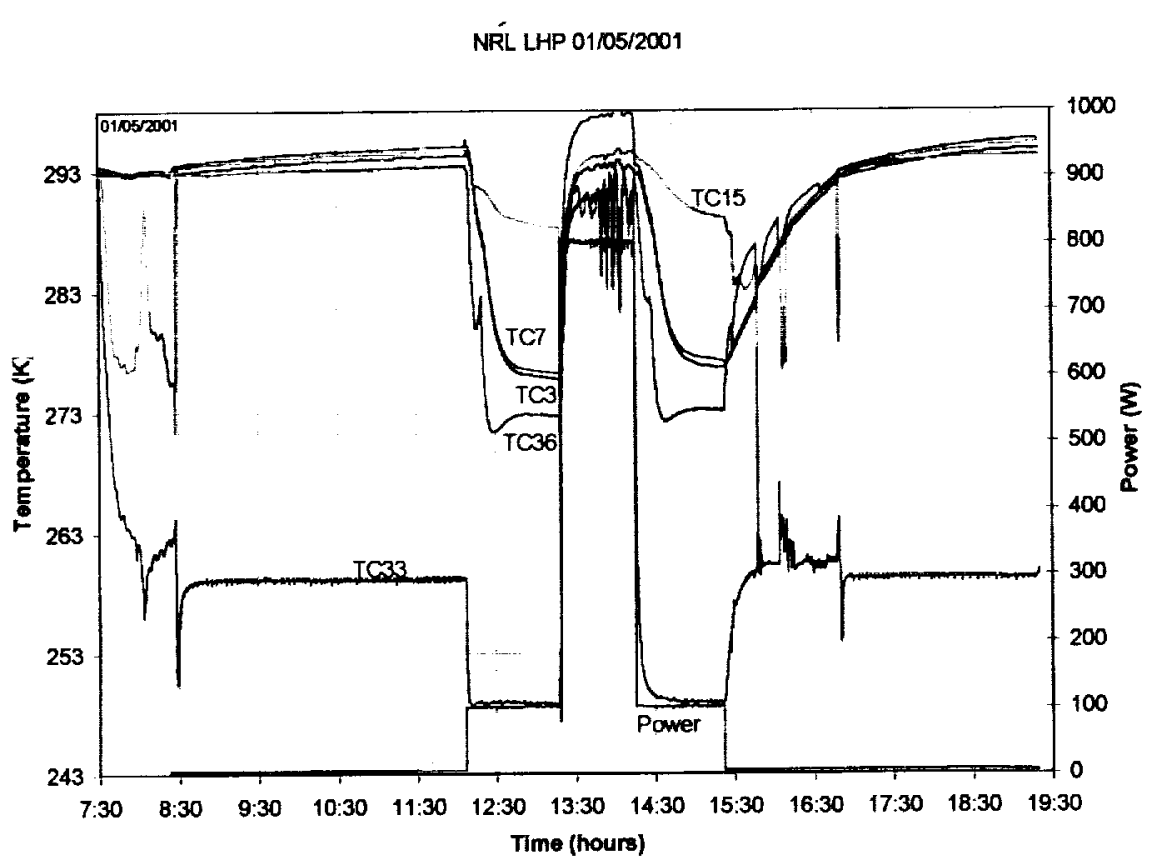

Figure $5 .(1 / 5 / 017: 30$ to $19: 30100 \mathrm{~g} / 6.35 \mathrm{~mm} / 5 \mathrm{~W} / 250 \mathrm{~K}$ start-up test followed by power cycle test

(TC3=CC, TC7=Evaporator, TC15=Vapor line, TC33/ TC36=Liquid Line)

NRL LHP $12 / 18 / 2000$

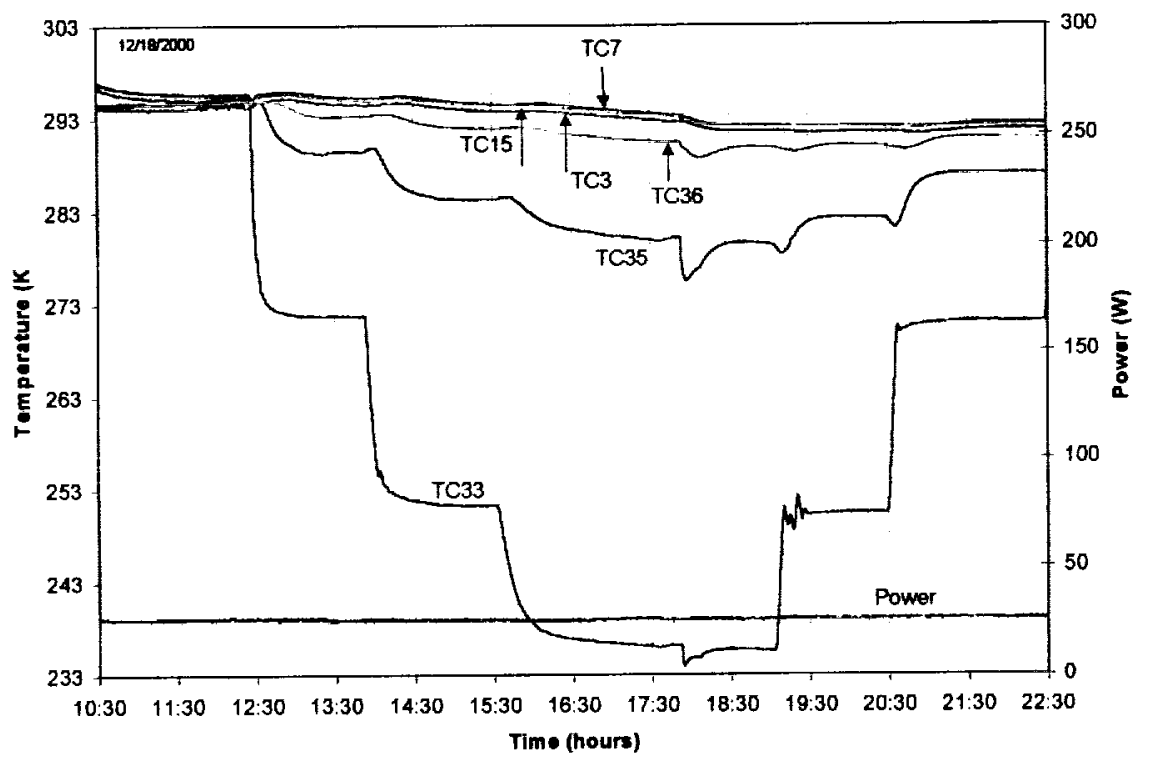

Figure 6. (12/18/00 10:30 to 22:30 with start-up and sudden temperature change at $25 \mathrm{~W}$ (TC3=CC, TC7=Evaporator, TC15=Vapor line, TC33/ TC35/ TC36=Liquid Line) 
NRL LHP 12/07/2000

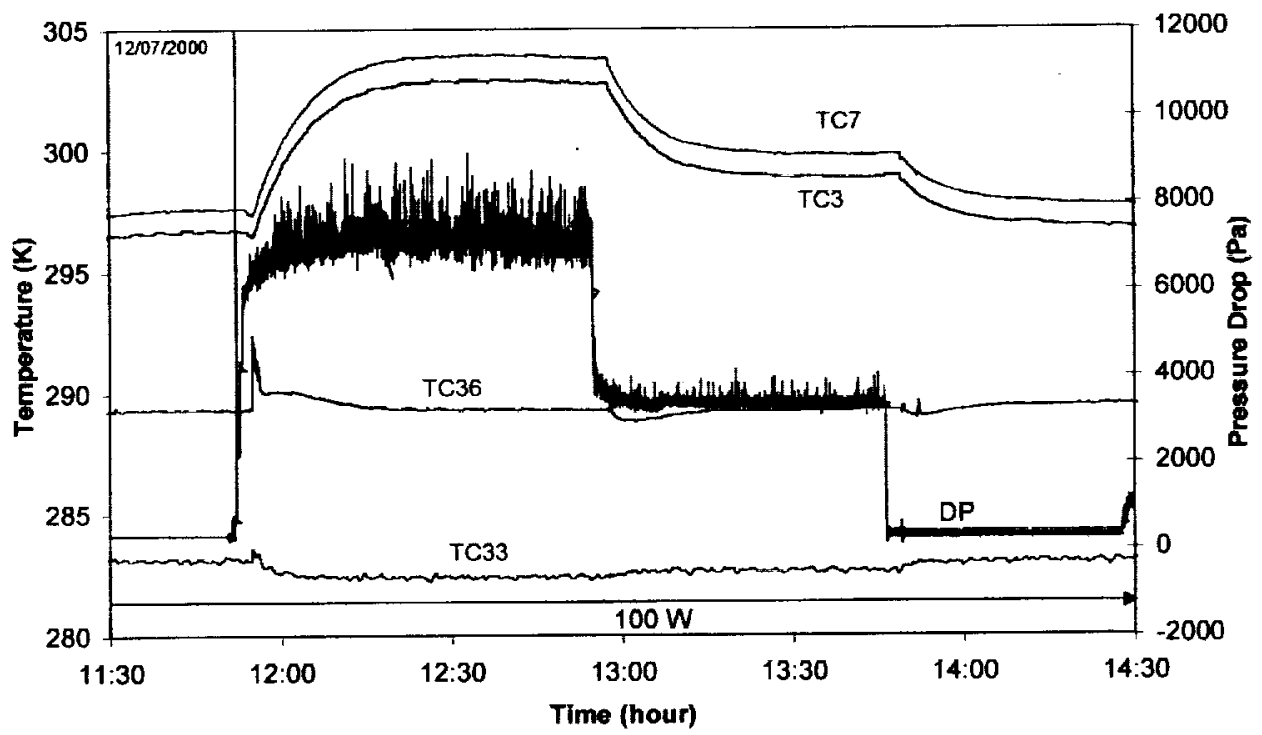

Figure 7. Effect of Pressure Drop on Loop Operating Temperature in the $(83 \mathrm{~g} /-6.35 \mathrm{~mm} /$ $100 \mathrm{~W} / 290 \mathrm{~K})$ Test

(TC3=CC, TC7=Evaporator, TC15=Vapor line, TC33/ TC35/ TC36=Liquid Line)

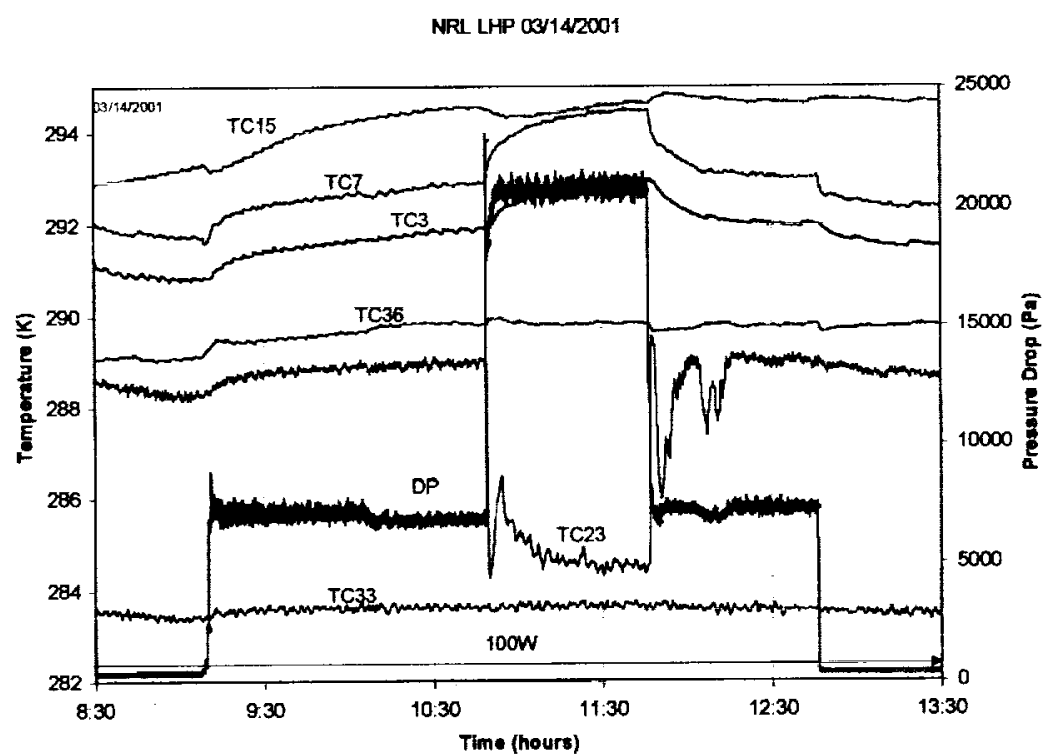

Figure 8. Effect of Pressure Drop on Loop Operating Temperature in the (113g/ $+6.35 \mathrm{~mm} / 100 \mathrm{~W} / 280 \mathrm{~K})$ test 


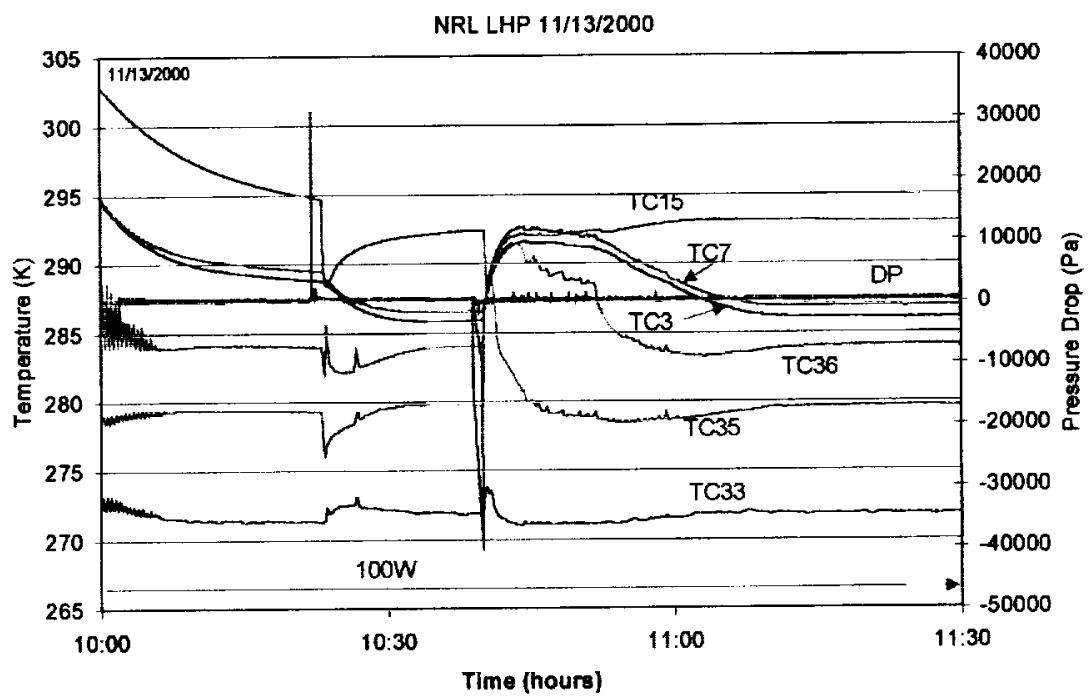

Figure 11. Sudden Temperature Change with $100 \mathrm{~W}$

(TC3=CC, TC7=Evaporator, TC15=Vapor line, TC33/ TC35/ TC36=Liquid Line)

NRL LHP 03-01:03-02 2001

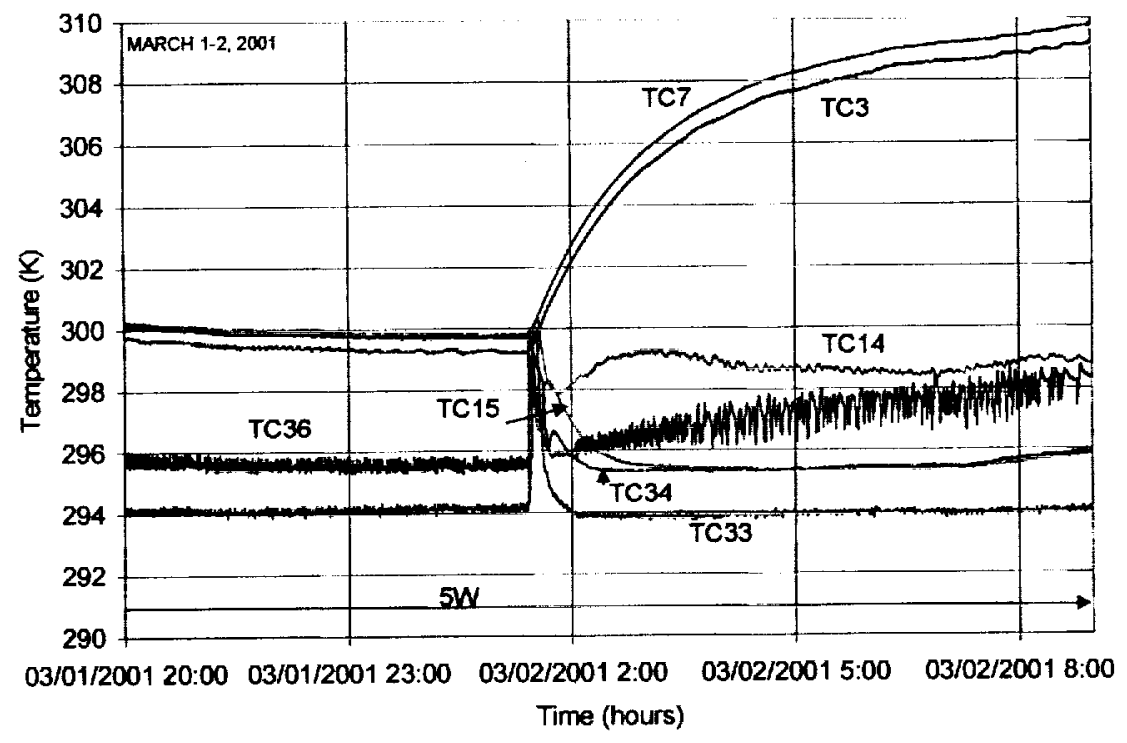

Figure 12. Sudden Change of Operating Temperature with $5 \mathrm{~W}$ Heat Load (TC3=CC, TC7=Evaporator, TC14/TC15=Vapor line, TC33/ TC34/ TC36=Liquid Line) 


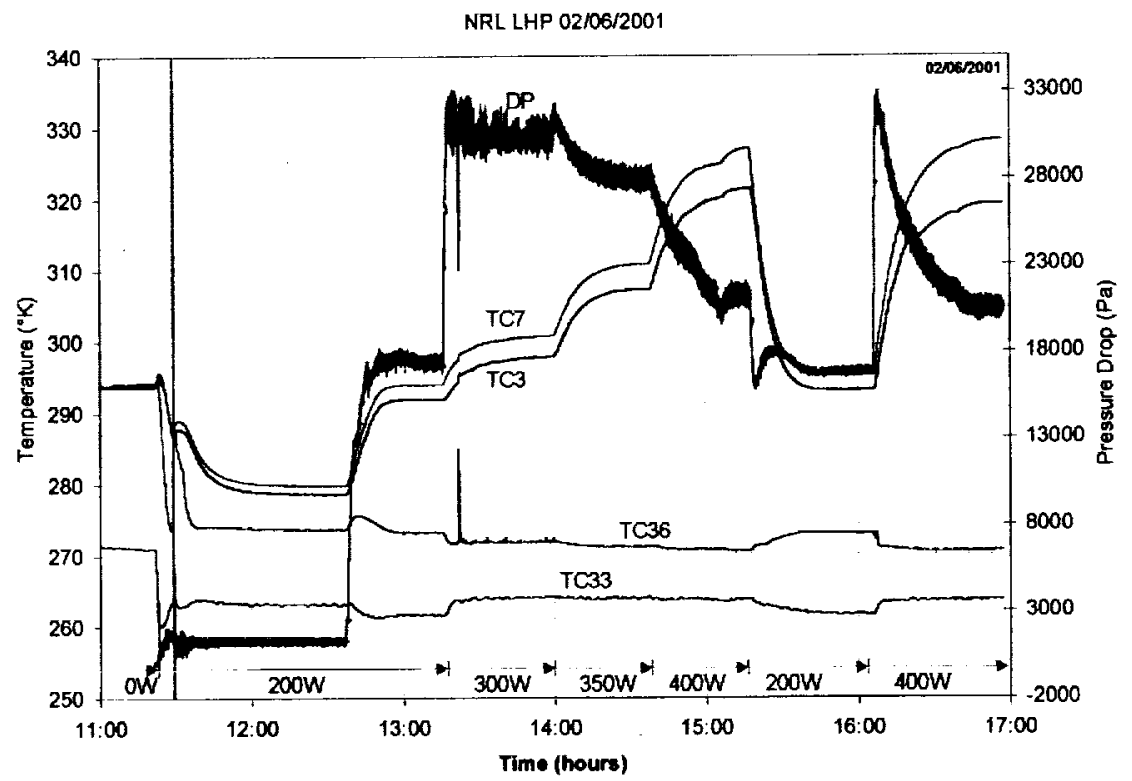

Figure 9. Capillary Limit (TC3=CC, TC7=Evaporator, TC15=Vapor line, TC33/ TC35/ TC36=Liquid Line)

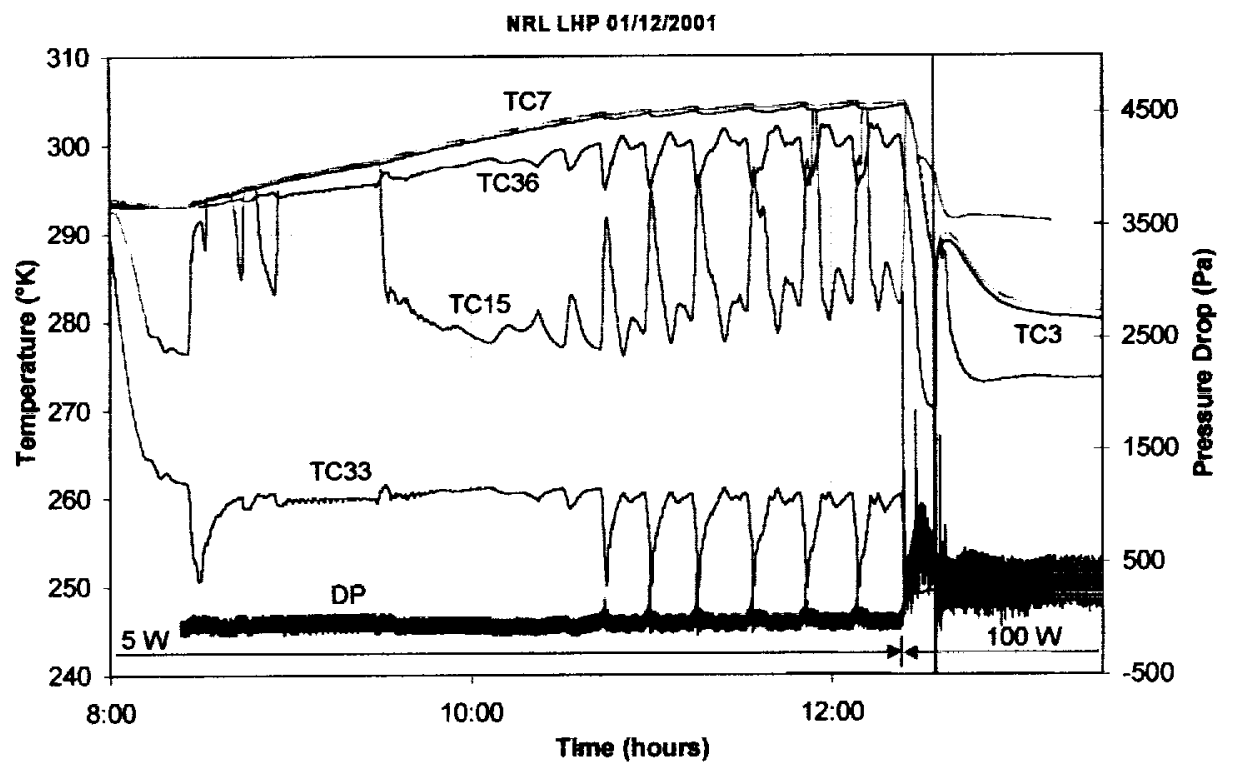

Figure 10. Temperature Oscillations with $5 \mathrm{~W}$ Heat Load (TC3=CC, TC7=Evaporator, TC15=Vapor line, TC33/ TC35/ TC36=Liquid Line) 